\title{
The Rhetorical and Argumentative Relevance of "Extreme Consequence" in Advertising
}

\author{
SAbrina Mazzali-LuRATI
}

Chiara Pollaroli

Daniela Marcantonio

\author{
Institute of Argumentation Linguistics and Semiotics \\ Università della Svizzera italiana \\ Via Giuseppe Buffi 13 - 6900 Lugano \\ Switzerland \\ sabrina.lurati@usi.ch \\ chiara.pollaroli@usi.ch
}

daniela.marcantonio@usi.ch

\begin{abstract}
The "extreme consequence" is a very common pattern in advertising messages that presents an odd, even negative, situation resulting from the use of the advertised product as a good reason to buy it. By analyzing selected advertisements employing this pattern using the conceptual integration theory and the Argumentum Model of Topics, we aim to understand how "extreme consequence" works at the rhetorical and argumentative levels. The analyses allow us to detect the typical, generic, cognitive, and argumentative structure underlying the pattern and to identify the rhetorical and argumentative role played by its main components, namely exaggeration and cause-effect relation.
\end{abstract}

Résumé: La «conséquence extrême» est un schéma très courant dans les annonces, par lequel une situation étrange, voire négative, résultant de l'utilisation du produit annoncé, est présentée comme une bonne raison pour acheter le produit lui-même. Nous employons la Théorie de l'intégration conceptuelle et le <<Argumentum Model of Topics>> pour analyser des announces publicitaires sélectionnés afin de comprendre comment la «conséquence extrême» fonctionne aux niveaux rhétorique et argumentatif. Ces analyses nous permettent de détecter la structure cognitive et argumentative typique et générique qui sous-tend le schéma et d'identifier le rôle rhétorique et argumentatif joué par ses principales composantes, à savoir l'exagération et la relation de cause à effet.

Keywords: advertising, Argumentum Model of Topics, Conceptual Integration Theory, extreme consequence, hyperbole 


\section{Introduction}

One of the main challenges in advertising - and also the fundamental one - is how to capture the viewers' attention (cf. Vaccaro 2016). Advertising creatives are well aware of this challenge and strive to create appealing messages and come up with stories, images, slogans, and rhetorical devices capable of conveying a multitude of competing messages (Mazzali-Lurati and Schulz 2014; Chan 2011, pp. 329-330). The "extreme consequence" (henceforth EC) is one of the tools that is quite frequently employed in order to address this challenge (cf. Goldenberg et al. 2009). Indeed, the EC tool proves to be very effective because by unexpectedly presenting an odd, even negative, situation as resulting from the use of the advertised product, it puzzles the viewers, it provokes them, and it automatically triggers a search for a plausible explanation of the (at least apparent) contradiction existing between the advertising character of the message and the situation represented in it. The discovery of that explanation then gives rise to joy and amusement that captures the viewers' attention more than any promise of effectiveness and satisfaction. ${ }^{1}$

Exaggeration and the presentation of a cause-effect relationship between the product and the situation represented in the ad are at the core of this tool. The component of exaggeration cannot but remind us of the rhetorical trope of hyperbole (Fontanier 1968; Pollaroli 2013; see Mazzali-Lurati and Pollaroli 2013 for an initial illustration with regards to Italian advertising). Several studies in linguistics, multimodality, rhetoric, and argumentation dealt with hyperbole (cf. Brdar-Szabó and Brdar 2010; Snoeck-Henkemas 2013; Ferré 2014; Grancea 2012). They pointed out fundamental features of this device, and of its use and its effects, which can be found also in ads employing EC. These features include: exaggeration (McCarthy and Carter 2004), distortion of reality (Gibbs 1994;McCarthy and Carter 2004), and contrast between what is

\footnotetext{
${ }^{1}$ The effect of humor in advertising is a topic of reflection and discussion in marketing and psychology studies where different positions are put forward by scholars. It is, however, generally accepted that humor enhances the viewers' attention to the advertising message and has a positive effect on the consumers' decisions (cf. Eisend 2009; Chan 2011; Strick et al. 2013).
}

(C) Sabrina Mazzali-Lurati et al. Informal Logic, Vol. 39, No. 4 (2019), pp. 497-530 
expected and what actually happens (Colston and Keller 1998) between 'speaker's discourse and listener's representations of the world" (Ferré 2014). But studies on hyperbole also underlined the presence of elusive aspects in it. Hyperbole seems to be so multifaceted and complex as to be hardly captured in a univocal definition. What role does hyperbole play in advertising messages featuring the EC pattern? What rhetorical and argumentative contribution does it have when intertwined with the cause-effect relationship of the product in the represented situation? The aim of this paper is to answer that question. By analyzing a (small and initial) set of advertisements employing EC, we aim to understand how this pattern, with its two cause-effect and hyperbolic components, works at the rhetorical and argumentative level. Starting from the assumptions that (1) advertisements put forth premises and conclusions by an integration of semiotic modes, and (2) monomodal/multimodal rhetorical tropes can correspond to argument schemes (Pollaroli and Rocci 2015), we will investigate how ads employing EC design the framing of the message and advance arguments in support of a standpoint. We will identify the inferences this pattern triggers in addressees and, more specifically, the inferences provoked by the cause-effect and hyperbolic component, thus clarifying what role hyperbole and cause-effect relation plays.

In the following sections, we will first describe examples of ads based on EC (and the effect in terms of the puzzlement and humour the addressee experiences in front of such texts) as well as describing the EC pattern itself as it is presented in the seminal literature on creative patterns in advertising (Goldenberg et al. 2009). Then, we will illustrate our analysis and introduce our methodological framework. Our hypothesis that the EC tool deploys tropes, which in advertising messages cannot but be multimodal (because they emerge both from verbal and visual elements of the text), justifies the consideration and application of the model for the analysis of multimodal tropes in page-based advertising messages proposed in Rocci et al. (2018). Using this model, we reconstructed the basic units composing the texts and their organization according to the text's layout, and we considered the visual structure and the contribution of the textual information. However, 
in the paper we focus more specifically on the analysis of the semiotic cognitive structure underlying the message under consideration using Conceptual Integration Theory (CIT), and on the reconstruction of the argumentative inferences at work in the text using the Argumentum Model of Topics (AMT). This analysis allows us to detect the typical, generic cognitive and argumentative structure of the EC pattern and to identify the rhetorical and argumentative role played by cause-effect relation and hyperbole.

\section{Odd advertisements: the "extreme consequence" pattern}

A young, pretty woman sitting on a train looks out of the window at a charming young man with a lovely bouquet of flowers. The young man looks at her quizzically, he appears disappointed and stunned. The young woman smiles; her expression and behavior are apologetic. She seems to say, "Sorry, but I'll stay here!" A man in business attire is sitting on a train and reading a newspaper. He avoids looking out of the window where an enchanting woman and a lovely little girl with a heart-shaped balloon that reads "Welcome home daddy!" are obviously waiting for him. The woman stares at him as if to say, "What? I cannot believe it!" and the man looks the other way with a guilty but firm expression in his face.

These two stories are told by two billboards by Irish Rail released in 2017 (cf. Fig. 1 in Appendix 1). ${ }^{2}$ These billboards were part of a company advertising campaign that also included a TV commercial in which the story of the business man as well as the final scene of the story of the young, pretty woman were developed (cf. Fig. 2 in Appendix 1). The businessman on the train has a video call with his wife and his little daughter during which he joyfully greets them and says, "Bye! See you at the station." A middle-aged woman sitting on the other side of the train knitting smiles her approval, which the man replies to with relief. Meanwhile, a woman and a little girl are enthusiastically entering the train station. The little girl holding a green balloon. On the train, the man is offered a hot beverage and his expression becomes nostalgic while he sits comfortably on his seat looking out the train

\footnotetext{
${ }^{2}$ We are grateful to Andrea Rocci who shared this example with us as soon as he came across it while he was in Dublin for a scientific conference.
}

(C) Sabrina Mazzali-Lurati et al. Informal Logic, Vol. 39, No. 4 (2019), pp. 497-530 
windows at the typical Irish landscape that is rolling by. The train reaches the station, and the woman and the little girl happily greet the man, who smiles at them while getting up from his seat. He is about to disembark, he grabs his coat, the teddy bear he bought for his daughter, and his drink, when something happens. His feet seem to be stuck to the train floor. He looks at his seat and at his drink, and his facial expression changes into a scared and guilty one. His wife looks astonished. His daughter looks sad. The man is not getting off! We hear the whistle of the train, and the man sits back in his seat gesturing apologetically to his wife who points angrily at their daughter. But the man is not looking at them anymore; he relaxes in his seat with a sigh of relief and a content expression on his face. The train departs, leaving the man's wife staring at him from the platform with a puzzled and disapproving expression and his daughter looking heartbroken while the balloon flies away.

In the ads of this campaign, the headline reads "so good you won't want to get off." This is actually an undesirable effect; if you travel on Irish Rail, instead of getting off and joining your loved ones and going home with them, you will prefer to stay on the train and continue your travel beyond your destination. Despite the undesirable effect that is depicted in the advertisements of this campaign, we smile and conclude that Irish Rail is a very valuable railway company that offers high quality services. This kind of argumentative strategy and reasoning is quite common in advertising. We also find it, for instance, in a TV commercial for the disinfectant by the German company Sagrotan broadcasted in 2016 (cf. Fig. 1 in Appendix 2).

A woman, who is automatically identified as a mother, cleans a table in a kitchen. A woman's voice from offscreen accompanies the cleaning activities explaining the properties of the cleaning product. The product, Sagrotan, is clearly visible with a prominent warning on the label that says to take caution when using this kind of product. After cleaning, the woman calls the family in to enjoy the dinner. Two children and a man, who is carrying a baby, come down laughing and cheering. But as soon as they look at the table, their facial expressions change, and they look at each other in astonishment. They sit at the table carefully and look with worry at 
the mother and at the table. There is no music, but the voiceover continues to explain about the high quality of Sagrotan, which seems in contrast to what is being conveyed by the facial expressions of the rest of the family. Then the frame expands so we can see exactly what is happening, namely, that the mother is serving the dinner directly on the table. Not only can we now better understand and justify the facial expressions, but we can understand what the family members feel. Everybody looks at the mother as if she is insane. The mother, however, looks self-confident. She has a satisfied expression that contrasts the reaction of the family. Eventually, she gives some carrots to the baby, who is the only one happily eating and the only one who does not care whether the carrots are on a plate or not. At this time, the voice stresses that Sagrotan cleans so well that you can eat off the table. The baby eats the carrots happily in contrast to the previous sequence in which the rest of the family looks uncertainly at the food wondering whether they should eat it or not. In order to break the awkwardness, the mother asks, with an amused expression, if anybody wants some dressing, and the family laughs out loud. The situation is now relaxed, and the family understands the mother's joke. Sagrotan then appears in the foreground. The slogan "sorglos sauber" (carefree clean) appears to be a summary of the sequences of the commercial.

The EC template has been described in seminal research on creativity in advertising. With the aim of understanding the recipe for successful advertising and developing a method for teaching how to create and enhance creativity in advertising, Goldenberg and his colleagues (Goldenberg et al. 1999; Goldenberg et al. 2009) analyzed advertisements that were awarded international prizes by professionals and identified a taxonomy of recurrent patterns that they called Creativity Templates. Among them we find the "consequences" family, later renamed "extreme" family. Advertisements employing the pattern of the Extreme Consequence replace the common cliché of extreme promise (Goldenberg et al. 2009, pp. 97-98) where the benefit brought about by the core positive attribute of the product is emphasized by displaying (and exaggerating) the positive result of enjoying or realizing the benefit. Goldenberg et al. (2009) stress that messages that use this 
strategy are very easy to understand but lack credibility. By contrast, in advertisements based on the EC tool, the benefit of the advertised product is emphasized by "another, similar extreme, but one that will solve the problem of credibility" (Goldenberg et al. 2009, p. 97). The message of the advertisement is built around the exaggeration in a negative direction of an effect derived from the use of the product (obviously, the effect that the company considers the most important one and that it wants to bring to the audience's attention). Therefore, "[w] hat we see in ads characterized by this tool is the absurd result of using a product or having it" (Goldenberg et al. 2009, p. 98) - a hyperbolic situation that is "an unexpected, accidental, and often negative scenario, arising as a consequence of the product's positive attribute" (Goldenberg et al. 2009 , p. 100). One of the examples of this pattern illustrated by Goldenberg et al. 2009 is a print ad for Sonicare toothbrush (cf. Fig. 1 in Appendix 3), in which the positive benefit of white teeth is emphasized by showing a group photograph where the faces are not visible because the people's teeth are so white that they reflect the camera flash (an undesirable effect for a photo that is usually shot as a souvenir or a memento document). The argument put forward in order to support the quality of the Sonicare toothbrush is quite odd and obviously different from that displayed in many other ads for dental products where the positive benefit of the advertised product is emphasized by showing very white teeth on the lovely face of a beautiful wide-smiling woman. The same advertising scheme was used by the Indian company, Grasim Suiting, in a series of ads for its summer fabric Aquasoft, which was launched in 2001 (cf. Figure 1 in Appendix 4). In the three different versions of the ad, the positive benefit of high comfort that can be experienced when wearing pants made with Aquasoft fabric was emphasized by showing negative unexpected situations arising from the fact that (as it is made explicit by the baseline of the ad) one could forget to have pants on. Pants made with Aquasoft fabric are so comfortable that you might forget to take them off when sitting on the toilet, you might dress without realizing that you already have pants on and you might cover yourself thinking that you are naked even if you have pants on. 
The route of communication proposed by the EC template clashes with the identification of the message as a promotional one and the following expectation that reasons will be provided to support the main message rather than reasons that oppose it. In fact, advertisements are enthymemes that put forth reasons in order to support a positive evaluation of a product and thus the standpoint: "Buy product X." If we were to follow the EC inferential path literally, we would infer that "We should not buy product $X$ " because it causes something undesirable on the basis of the argumentation scheme of termination and setting up (see Serafis et al., 2019) and the procedural premise "if an object causes something undesirable, it is desirable not to use it." Now starting from the assumption that advertisements, by an integration of semiotic modalities, put forth premises in order to support the claim that a product is worth buying, we will investigate how the negative, unexpected situations displayed in the ads employing the EC pattern advance arguments in support of the standpoint of buying or using the advertised product or service. Particularly, we will investigate how the hyperbolic component of exaggeration and the component of cause-effect relation contribute to this argumentation. We examine the four, above-described advertisements with the goal of first reconstructing the semiotic cognitive structure of their messages, then going on to analyze their enthymematic argumentative structure.

\section{The cognitive and argumentative structure of a selected sample.}

Our analysis will employ the theoretical framework and the conceptual tools elaborated within the Conceptual Integration Theory (CIT) in conjunction with the Argumentum Model of Topics (AMT) as developed in earlier research conducted at IALSInstitute of Argumentation Linguistics and Semiotics (MazzaliLurati and Pollaroli 2016; Pollaroli and Rocci 2015; Rocci et al. 2018). Thanks to this analysis, we will be able to draw some conclusions about the typical, generic, rhetorical, and argumentative structure of messages using the EC pattern. 
Conceptual integration is a fundamental process of meaning construction, which, as a central process in human reasoning, is capable of explaining the emergence of totally novel meaning structures (Fauconnier and Turner 1998, p. 134) particularly in cognitive operations such as counterfactuals and tropes. With CIT, it is possible to identify the mental spaces that compose the message and the cognitive mechanism that results from the connections between them (Fauconnier and Turner 2002). The new emergent structure is conceived of as a blended space, resulting from the projection of some selected features of at least two different mental spaces (the input spaces) under the governance of a generic space. The input spaces are "structured by information from discrete cognitive domains" while the generic space "contains structure common to all spaces in the network" (Coulson and Oakley 2000, p. 178).

The following argumentative analysis with the AMT model (Rigotti and Greco 2019; Rigotti and Greco Morasso 2010; Rocci 2017) will allow us to further investigate the relationship between the detected mental spaces and the EC pattern in order to verify the possibility that the pattern has an inferential function in the structure of the argument put forward in the ad. The mental spaces we could single out by the analysis of the conceptual integration process (input spaces, blended space, and, especially, the generic space) enable the identification of the premises on which the argumentative inferences are based (Pollaroli and Rocci 2015, p. 171, Rocci et al. 2018, p. 12). Referring to the inferential enthymematic structure of argument as described by AMT, these properties are elements from which we can reconstruct the materialcontextual component of the argument which then combines with the procedural-inferential component leading to the final conclusion (Rigotti and Greco 2019, p. 209). Namely, from the properties of the mental spaces we can reconstruct the datum (specific facts of the case) and the endoxon (a culturally taken-for-granted or easily recognizable generalization (cf. Pollaroli and Rocci 2015, p. 178; Rocci et al. 2018, p. 13), as well as the conceptual relation (locus) licensing the inferential structure of the argument (Rocci 2017). 


\subsection{The case of Irish Rail}

The Irish Rail ad has a humorous effect on viewers generated by what Coulson (2001) calls frame-shifting. A scenario is presented that violates the audience's expectations, which are based on the invoked knowledge of the events of a scenario of this type (p. 49). The inconsistency between presentation and expectation causes the audience to reanalyze the situation, leading to a shift in the frame invoked (p. 59). For us, this veer in the interpretative work causes, at first, puzzlement, and then, when the humoristic solution is presented, a pleasant satisfaction, which enhances the memory of the advertisement and thus its effect.

The situation presented in the final scene of the Irish Rail commercial (a man is travelling back home with Irish Rail and is not willing to get off even though he is looking forward to meeting his family) does not correspond to (it even contradicts) the common idea of homecoming, which we conceive as being characterized by the desire to meet our loved ones. This is a "novel conceptualization" (Coulson and Oakley 2000, p. 176) of homecoming that gives rise to different inferences and emotional reactions as compared to the "canonical" one. With respect to the usual representation of a husband and father or of a woman and fiancé arriving at the train station, this ad puts forward a novel emergent meaning structure (Coulson and Oakley 2000, p. 180). From a cognitive point of view, this structure is the final result of a conceptual integration of different mental spaces, which represent the common experience of coming back home (particularly after a business trip), the experience of travelling by train, as well as the advertised possible experience of the services offered by Irish Rail.

The semiotic elements composing the ad and the multimodal integration of them in the layout and montage contribute to the representation of two cognitive domains: the cognitive domain of homecoming after a trip (with all its commonly experienced emotions such as the desire to meet the loved ones, the desire to stop travelling, the delight to be waited for and picked up at the station) and the cognitive domain of travelling on Irish Rail trains (and as it is narrated in the tv commercial-benefitting from the partic- 
ular services offered on them including drinks, the possibility to relax and look at the scenery, and the possibility to be among nice people). From the projection of the features of these two input spaces, a blend then arises consisting of the odd, new, situation represented in the ad of someone who is at the end of his trip on Irish Rail, and who, although being expected to experience the delight of homecoming, decides not to get off, and to stay on the train instead and to continue travelling in order to continue benefitting from Irish Rail's good service (cf. Figure 3 in Appendix 1). The projection is governed by a generic space underlining the desirability of well-being. Indeed, the odd situation represented in the ad and constituting the blended space derives from the emergence in the situation of a new source of well-being (the high quality of a trip with Irish Rail) that is different from the commonly expected one (meeting one's family).

But how does this cognitive structure let us infer that it is worth travelling by Irish Rail? In order to answer this question, a further analytical step is required with the aim of shedding light on the argumentative inferences at work in the ad. All the mental spaces composing the cognitive structure of the message are argumentatively relevant; they activate the standpoint(s) advanced in the ad and the arguments in support of them.

More precisely, here, the story told in the Irish Rail TV commercial and summarized in the billboards of the campaign works as a factual premise of a complex conclusion that intertwines two lines of reasoning: a line of reasoning that leads the audience to discover that the service is good, and a line of reasoning that leads the audience to infer that the service is worth choosing (cf. Fig. 4 in Appendix 1). The factual premise (or datum) puts the absurdity of the situation before the eyes of the audience; a believable, commonplace story is told but at a certain point there is a shift in the situation that puzzles the audience. The audience knows and expects that when one travels back home after a trip, meeting their family is desirable and is commonly considered as an important value. But the behaviour of the protagonist of the story told in the ad clashes with the common expectation of how the situation should go. When the character chooses to stay on the train and continue the trip instead of getting off and meeting his family, he 
makes an uncommon decision and inverts the normal values. This unexpected and absurd turn of events leads the audience look for a cause by activating a procedural premise (or maxim) of the type "If a person chooses X instead of an important value/desire, then $\mathrm{X}$ must be very good." The locus from final-instrumental cause (Rigotti and Greco 2019, p. 259) is at work here and it leads the addressee to infer that the services offered on Irish trains are of high quality. This conclusion serves as a factual premise (datum) for a pragmatic line of reasoning that corresponds to the construction or confirmation of desirability, which is typical for advertisements of products and services (Pollaroli and Rocci 2015, p. 164). By the activation of the acceptable premise "It is desirable to travel on good trains that make your trip comfortable," and the pragmatically inferred high quality of the Irish Rail service, and by the exploitation of the maxim "If X causes something desirable, it is desirable to use it" from the locus from final cause (Rigotti and Greco 2019, p. 258; Rigotti 2008), the desirability of Irish Rail is inferred and accepted.

\subsection{Examples from Goldenberg et al. (2009). The case of Sonicare and Aquasoft}

In the advertisement for the Sonicare electric toothbrush, the awkward situation that the viewer sees - a group photograph where the faces are not visible because of the dazzling brightness of the camera flash reflected on the shiny teeth of the people being photographed - is also the result of a blending operation (cf. Fig. 2 in Appendix 3). Under the governance of a generic space, which represents the common knowledge that "very clean objects become shiny," projections from two input spaces are exploited in order to give rise to that blend. The involved input spaces are that of photography, which encompasses elements such as the photographer, the camera, people being photographed, different kinds of photographs such as souvenir photos as memento documents, the effect of iconic representation, and the effect of brushing teeth with the Sonicare toothbrush. The underlying cognitive structure corresponds to an argumentative structure encompassing two arguments by final-instrumental cause (cf. Fig. 3 in Appendix 3). 
From the datum corresponding to the blended space and provided by the picture and the pack shot of the ad (teeth reflect the camera flash) and from the endoxon according to which "very clean objects become shiny and reflective," the first conclusion that "The teeth of these people (who used Sonicare) are shiny and reflective" is drawn. Activating the maxim that states the quality of the instrument on the basis of its unusual effect, derived from the locus from final-instrumental cause, this first conclusion leads viewers to infer the final conclusion that "the Sonicare toothbrush cleans teeth very well." This final conclusion becomes the datum of a superordinate argument, and on the basis of the endoxon, "It is desirable to properly clean one's teeth," it gives rise to the first conclusion that "the Sonicare toothbrush causes something desirable." Thanks to the maxim (derived from a locus from finalinstrumental cause) stating that it is desirable to use something that leads to desirable results, this first conclusion lets viewers infer the final conclusion that "it is desirable to use the Sonicare toothbrush."

Similarly, the cognitive structure underlying the different ads comprising the Acquasoft pants campaign is based on the conceptual integration between the mental space of wearing Aquasoft pants and, respectively in the three variations of the ad, the action of going to the toilet, getting dressed, and covering oneself. This blending operation is governed by the generic space "comfort is desirable and welcome" (cf. Fig. 2 in Appendix 4). The mental spaces and their features involved in this conceptual integration constitute the premises of the arguments that the viewers are invited to infer from the ads (cf. Fig. 3 in Appendix 4). The situation depicted in the ad and corresponding to the blend is a datum. Together with the endoxon, highlighting a behaviour that is normally adopted in the depicted situation and that relates to the need to not feel restrained or irritated by clothing leads to a first conclusion that "the man wearing Aquasoft pants feels naked." By the maxim of the locus from final-instrumental cause stating that "If an instrument $X$ causes an unusual effect, $X$ is effective," the final conclusion can be drawn that "Grasim pants made with Acquasoft are unperceivable." This conclusion then becomes the datum of an argument by final-instrumental cause, which, via the first conclu- 
sion "Grasim causes something desirable" (drawn on the basis of the endoxon "unperceivable pants are desirable in order to feel comfortable") and the maxim associated to the locus, leads to the final conclusion "It is desirable to use Grasim Acquasoft pants."

\subsection{The case of the Sagrotan commercial}

Humor and puzzlement are experienced also when viewing the commercial for the Sagrotan disinfectant. The mother's decision to set the table for the meal without dishes and to serve the food directly onto the table clashes with our common idea of the proper preparation of the table for a meal. The members of the family, who represent our culturally shared way to eat (not the baby, who is not yet acquainted with cultural norms), express their puzzlement and, subsequently, understand the humoristic approach of the mother. In contrast to the first impression, the argumentative line of the commercial and the action of the mother are not in conflict but rather support the efficiency of the product and the high quality of Sagrotan. As already highlighted above, the figure of the mother plays a central role; she is the main character of the ad, the one that brings the action forward and gives rise to the awkward situation constituting the blend. Accordingly, she has a prominent place in the cognitive structure of the ad, which is then reflected also in the argumentative structure.

Here the blend consists of the mother, and the action of putting the meal directly on the table (cf. Fig. 2 in Appendix 2). The latter is the result of projections of selected features from three different input spaces under the governance of a generic space that contains our ideas of hygiene for human beings (such as "Hygiene is necessary for a healthy life, particularly when it comes to basic human needs, such as eating"). Input space 1 contains the usual and common habits of serving food and preparing a meal, which includes the fact that the table has to be cleaned and properly set and that plates are used. Input space 2 is built around the figure of the mother, who is commonly recognized as knowing how to properly take care of a house and of a family. The third input space represents the highly effective action of cleaning with Sagrotan disinfectant, which guaranties "sorglos sauber." 
As it emerges in input space 2, the mother in the commercial represents all the mothers in the world and appeals to the protective instinct, which all mothers have, activating the locus from authority with the maxim: "If $\mathrm{p}$ is said by an expert in the domain in which p belongs, $p$ is true" (cf. Fig. 3 in Appendix 2). Actually, it is precisely this protective instinct that guides the story and allows the addressee to understand and justify the exaggerated action of the mother. She blindly trusts Sagrotan, and as a natural and logical consequence of this, she serves the dinner directly on the table (as summarized in the first conclusion). The enthymematic reasoning is clear and leads directly and without any doubt to the first and to the final conclusions because the common understanding of this type of product is that they disinfect and eliminate most of the germs. But even if the statement "so clean that you can eat off it" is equivalent to perfectly clean, this does not mean that we really would eat from the table. In this sense, the behaviour of the mother is an extreme consequence induced by the high performance of the product and following the maxim "If an action carried out by instrument $\mathrm{X}$ brings about a result out of the norm, $\mathrm{X}$ is effective." The final conclusion, immediately inferred, links the extraordinary cleanliness of the table to the product thereby showing the outstanding properties of Sagrotan.

So, the action of the mother serving directly on the table, which seems to be normal and straight-forward, contrasts with the common meal habits of a family. The husband and the children look at the mother with astonishment and some worry, and their facial expressions indicate to the viewer that something is going wrong. Afterwards, we see what the mother is actually doing and we automatically understand the joke; the product's quality has this effect on the mother and her exaggeration, which puts the words "sorglos sauber" into action, makes us smile. The mother challenges the family by looking everyone in the eye with satisfaction and a self-confident facial expression, implicitly saying "I know what I am doing." According to Marcantonio (2016), the intentional facial expression, gesture, and sometimes body posture are a highly efficient means of communication as they convey established and easily accessible concepts, and they do not need to be verbalized in order for the message to be understood. Notwith- 
standing this, the family does not touch the food, but only the baby grabs the carrots and eats them happily. The simplicity of the baby and his trust in his mother has a rhetorical effect. It highlights once again the oddness of the situation as the baby-not acquainted with cultural knowledge of serving food - does not mind eating off the table. Now, the mother dissolves the awkward situation by offering some dressing, and everybody starts to laugh recognizing that the situation is too extreme to be considered serious, and paradoxically, everything becomes funny.

\section{Discussion}

The same cognitive and argumentative structure can be found in all the analyzed examples. This regularity of results enables us to suppose that the routes of inference described above are the common cognitive and argumentative structure that forms the basis of the EC pattern. In the advertisements, the blending operation, which describes the cognitive process required for the interpretation of the advertisement, consists of a conceptual integration between the mental space corresponding to the action of using the advertised product (which in the graphical representations in the appendixes we identify as input space 2) and the mental space of another action (identified as input space 1). The integration between these two mental spaces is governed by a generic space corresponding to a characteristic of the advertised product, which is relevant in respect to the action constituting input space 1. Projections from these three mental spaces give rise to the blended space, representing the awkward situation expressed in the ad. The presence of a third input space in the case of the Sagrotan commercial should be related to the mother's special role in the story. However, it does not exclude (it even requires) the presence of the other two input spaces.

The argumentation stemming from this cognitive structure is based on intrinsic argumentation schemes of the causal type (Rocci 2017 , p. 55). Indeed, in all the analyzed cases, the argumentative structure entails two inferences based on the locus of finalinstrumental cause. The odd situation resulting from the story told in the ad (the blended space) corresponds to a datum, which works 
as a factual premise in the material-contextual dimension of the inference that leads to the conclusion and recognition of the awkwardness of the situation. The endoxon (which works as a general premise in the underlying syllogistic structure) consists of elements of the first input space and of the generic space of the blending operation and represents the normal habit or behavior related to the action constituting input space 1 . The clash between the endoxon and the datum prompts the search for the origin of the oddness and activates the locus from final-instrumental cause and the maxim stating the high-quality of the cause of the situation in the datum. The combination of this procedural-inferential dimension and of the above-described material-contextual dimension leads then, as a final conclusion, to the recognition of the quality of the product present in the datum. This conclusion works as the datum of the second inference composing the argumentative structure of the ad. Together with an endoxon stating the desirability of the quality offered by the product, it leads to the conclusion that the product itself is desirable. This first conclusion works then as a minor premise in an argument from final-instrumental cause that, based on a maxim stating that if something has a good effect it is desirable to have it, leads to the conclusion that it is good to buy the product.

By means of the first argument, the audience discovers the "goodness" of the product or service, while by means of the second argument, the audience discovers the "worthiness" of the product (which should then lead to the decision to buy or use the product or service) - a conclusion that is drawn from its desirability. This is the typical argument of advertising, that is, a pragmatic argumentation (Rigotti and Greco 2019, p. 259) where inference is used to justify decisions about possible actions (cf. Hitchcock 2001).

However, beyond this common cognitive and argumentative structure some differences have to be noticed in order to shed light on the nature of the exaggeration component of the message. ${ }^{3}$ The

3 The difference between the analyzed ads is perceived also because of the different semiotic modes employed; the temporal unfolding of the narration in the commercials gives access to many details of the story that can only be (C) Sabrina Mazzali-Lurati et al. Informal Logic, Vol. 39, No. 4 (2019), pp. 497-530 
examples proposed by Goldenberg et al. 2009 embody EC in a purer form since they depict awkward situations that simply occur because of the product; the use of the product results in a particular effect which the protagonist of the ad experiences as negative. In the two other analyzed examples, however, the narrated awkward situation is the result of a choice made by the protagonist of the ad due to the fact that they experience the effect of the product to be positive (although it is experienced as negative by the protagonist's family in both cases). In argumentative terms, in the ads for Sonicare and Aquasoft, the maxim derived from the locus from final-instrumental cause in the first argument focuses on the effectiveness of the product as an instrument for the action represented in the datum; it presents the unusual effect as a consequence of the effectiveness of the instrument. Between the instrument and the effect it causes, there exists an exaggeration based on quantity (Brdar-Szabó and Brdar 2010). The product as instrument can cause that effect only because its "power" is exaggerated, and consequently, it gives rise to a hyperbolic situation focusing on a side effect of the action of using the product. In the case of the Sagrotan commercial, we have the same kind of maxim and the same kind of relation between product and effect. However, here the situation narrated in the datum is not a side effect of the action of using the product but an outcome intentionally pursued by the mother as a character in the commercial. The negative side effect (the initial mistrust of the family towards the mother) is present and shown, but it is not the element of the action at the center of the message. Instead, the focus here is on the decision of the mother - a hyperbolic decision that gives rise to a hyperbolic action, which is then highlighted in the maxim (cf. Figure 3, Appendix 2).

The case of the Irish Rail ad is similar. Here the viewer is presented with the hyperbolic action of the main character. Its side effect (the sadness or anger of the family) is shown in the ad, but the central focus of the message is on the goal the main character

hinted at in the spatial construction of a page-based document such as a billboard (Bateman 2008; Wildfeuer and Pollaroli 2018). 
envisages and pursues. The maxim sheds light on this goal or outcome as if it was caused by a hierarchy of values being subverted; the pleasure of enjoying what the product (the train) offers becomes more important than the unquestionable value of meeting one's family. Here the exaggeration corresponds to the fact that the product becomes a value that acquires importance and rises higher in the hierarchy of values.

Maxims of this kind are activated by the situation constituting the datum and its awkwardness in respect to the endoxon. They are invoked in response to the anomaly related to the product, which emerges in a common and recognizable situation. We can say, then, that the exaggeration arises in the maxim starting from the clash between the endoxon and the datum and on the basis of the cause-effect relation existing between the product and the narrated situation. This shows an isomorphism between the hyperbolic situation depicted in the message and the locus of finalinstrumental cause and the maxim derived from it. The hyperbolic and cause-effect relation are both argumentatively relevant, that is, they are essential for triggering the proper argumentative inference. We are faced with a procedure of the inference that "epitomize[s] lines of reasoning" (Fahnestock 1999, p. 23).

However, it is not completely justified that an effect out of the norm results from the high efficacy of the product. It could be the case, but there could be other reasons for this. Indeed, we have here a "ceteris paribus" situation. As Pollaroli and Rocci (2015, p. 187) explain, the expression ceteris paribus, meaning "all other things being equal," signals that the maxim is defeasible and there might be other causes for the same effect (see Rigotti 2008 on the defeasible or demonstrative nature of maxims, which are also called "paramaxims"). But why, in the cases considered here, is the proposed argument not defeated? The gap between an effect that is out of the norm and the efficacy of the product is filled by the addressee based on the recognition of the causal chain explaining the product's existence (a company produces a product that when used, has a particular effect) and as a result of the awareness of the rules of the context of advertising (companies think that their products are good and want to convince consumers that this 
is the case). ${ }^{4}$ As receivers of the ads, we accept the paramaxim (Rigotti 2008, p. 567) because we know how advertising works and we agree to take part into the ludus that advertising offers. This acceptance is what makes the pattern rhetorically strong.

\section{Conclusion}

In this paper, we analyzed a sample of advertising messages employing the EC pattern from a cognitive point of view (by means of CIT) and from an argumentative point of view (by means of AMT) in order to understand how such messages put forward positive arguments supporting the fundamental message of advertisements: "it is worth buying X."

In our analysis, we singled out the different roles and contributions of the two fundamental components of the pattern, namely, the exaggeration and the cause-effect relation, and we identified the typical cognitive and argumentative structure of the EC pattern in which both components proved to have an argumentative and rhetorical function.

Our sample was small and preliminary and certainly our analysis could be further validated by an extension of the set and through comparison with an analysis of enthymematic messages in advertisements that take a hyperbolic "traditional" route (i.e. that claim the extreme attribute and benefit of a product). However, the results we obtained offer an important contribution in the exploration of the relation existing between rhetorical advertising strategies, multimodal tropes, and argumentation carried out at IALS during the last decade. At present, these results confirm that creative patterns in advertising correspond to regular and recurrent argumentative structures.

\footnotetext{
${ }^{4}$ It has to be noted that the operation by which the audience fills in the gap entailed by the paramaxim is completely left to the audience's initiative. The difference between communicated inference and communicative inference (Rocci 2006) is then at issue, that is the difference between an inferential path set and openly offered by the proponent of the message and an inferential path that is left to the audience to unveil. However, we are not exploring this topic further in this contribution as it requires more space and more effort by all members of the research team at IALS.
}

(c) Sabrina Mazzali-Lurati et al. Informal Logic, Vol. 39, No. 4 (2019), pp. 497-530 


\section{Acknowledgments:}

We deeply thank the two anonymous reviewers for their helpful comments.

\section{References:}

Bateman, John A. 2008. Multimodality and genre. A foundation for the systematic analysis of multimodal documents. Basingstoke/New York. Palgrave MacMillan.

Brdar-Szabó, Rita and Mario Brdar. 2010. "Mummy, I love you like a thousand ladybirds": Reflections on the emergence of hyperbolic effects and the truth of hyperboles. In Tropical truth(s): The epistemology of metaphor and other tropes, eds. Armin Burkhard and Brigitte Nerlich, 383-427. Berlin \& New York: Mouton de Gruyter.

Chan, Fong Yee. 2011. Selling through entertaining: The effect of humour in television advertising in Hong Kong. Journal of Marketing Communications 17 (5): 319-336.

Coulson, Seanna. 2001. Semantic Leaps: Frame shifting and conceptual blending in meaning construction. Cambridge. Cambridge University Press.

Coulson, Seanna and Todd Oakley. 2000. Blending basics. Cognitive Linguistics 11 (3): 175- 196.

Eisend, Martin. 2009. A meta-analysis of humor in advertisement. Journal of the Academy of Marketing Science 37: 191-203.

Fahnestock, Jeanne. 1999. Rhetorical figures in science. New York. Oxford University Press.

Fahnestock, Jeanne. 2004. Figures of argument. Informal logic 24(2): 115-135.

Fauconnier, Gilles and Mark Turner. 1998. Conceptual integration networks. Cognitive Science 22(2): 133-187.

Fauconnier, Gilles and Mark Turner. 2002. The way we think. New York. Basic Books.

Ferrè, Gaëlle. 2014. Multimodal hyperbole. Multimodal Communication $3(1): 25-50$.

Goldenberg, Jacob, Mazursky, David and Sorin Solomon. 1999. The fundamental templates of quality ads. Marketing Science 18: 333351.

Goldenberg, Jacob, Lebab, Amnon, Mazursky, David and Sorin Solomon. 2009. Cracking the ad code. New York. Cambridge University Press. 
Grancea, Ioana. 2012. When images hurt: a closer look at the role of negatively-valanced images in advertising. Argumentum: J Semin Discursive Logic. Argumentation Theory Rhetoric 10: 153-164.

Hitchcock, David. 2001. Pollock on practical reasoning. Informal Logic 22(3): 247-256.

Marcantonio, Daniela. 2016. Gesten im interkulturellen Vergleich. Berlin. Frank \& Timme.

Mazzali-Lurati, Sabrina and Chiara Pollaroli. 2013. A vantaggi estremi, estrema creatività. Una caratteristica della pubblicità italiana. Cultura \& Comunicazione IV/4: 59-65.

Mazzali-Lurati, Sabrina and Chiara Pollaroli. 2016. Blending metaphors and arguments in advertising. In Metaphor and Communication, eds. Francesca Ervas and Elisabetta Gola, 498-525. Amsterdam: John Benjamins.

Mazzali-Lurati, Sabrina and Peter Schulz. 2014. Attention in context: from ancient rhetoric to contemporary communication sciences. In Language, reason and education. Studies in honor of Eddo Rigotti, eds. Andrea Rocci and Giovanni Gobber, 217-231. Bern: Peter Lang.

Pollaroli, Chiara. 2013. T(r)opical patterns in advertising. In Virtues of Argumentation. Proceedings of the $10^{\text {th }}$ international conference of the Ontario Society for the Study of Argumentation (OSSA), eds. D. Mohammed, M. Leviński. Winsor: OSSA.

Pollaroli, Chiara and Andrea Rocci. 2015. The argumentative relevance of pictorial and multimodal metaphor in advertising. Journal of Argumentation in Context 4(2): 158-200.

Rigotti, Eddo. 2008. Locus a causa finali. L'Analisi Linguistica e Letteraria 16(2): 559-576.

Rigotti, Eddo and Sara Greco. 2019. Inference in argumentation: A topical approach to argument schemes. Amsterdam: Springer.

Rocci, Andrea. 2006. Pragmatic inference and argumentation in intercultural communication. Intercultural Pragmatics 3(4): 409-442.

Rocci, Andrea. 2017. Modality in argumentation. A semantic investigation of the role of modalities in the structure of arguments with an application to Italian modal expressions. Amsterdam: Springer.

Rocci, Andrea, Mazzali-Lurati, Sabrina and Chiara Pollaroli. 2018. The argumentative and rhetorical function of multimodal metonymy. Semiotica (220): 123-153.

Serafis, Dimitrios, Greco, Sara, Pollaroli, Chiara and Chiara Jelmini Martínez Soria. (2019). Towards an integrated argumentative approach to multimodal critical discourse analysis: Evidence from refu- 
gees and immigrants' portrayals in Greek newspapers. Critical Discourse Studies. https://doi.org/10.1080/17405904.2019.1701509

Snoeck-Henkemas, Francisca A. 2013. The use of hyperbole in the argumentation stage. In Virtues of Argumentation. Proceedings of the $10^{\text {th }}$ international conference of the Ontario Society for the Study of Argumentation (OSSA), eds. Dima Mohammed and Marcin Leviński. Winsor: OSSA.

Strick, Madelijn, Holland, Rob W., van Baren, Rick B., van Knippenberg, Ad and Ap Dijksterhuis. 2013. Humor in advertising: An associative processing model. European Review of Social Psychology 24(1): 32-69.

Vaccaro, Claudio. 2016. Native advertising. La nuova pubblicità. amplificare e monetizzare i contenuti online. Milano. Hoepli.

Wildfeuer, Janina and Chiara Pollaroli. 2018. Seeing the untold. Multimodal argumentative strategies in movie trailers. In Multimodal argumentation and rhetoric in media genres, eds. Charles Forceville and Assimakis Tseronis, 189-215. Amsterdam: John Benjamins.

\section{Appendix 1. Irish Rail 2017}
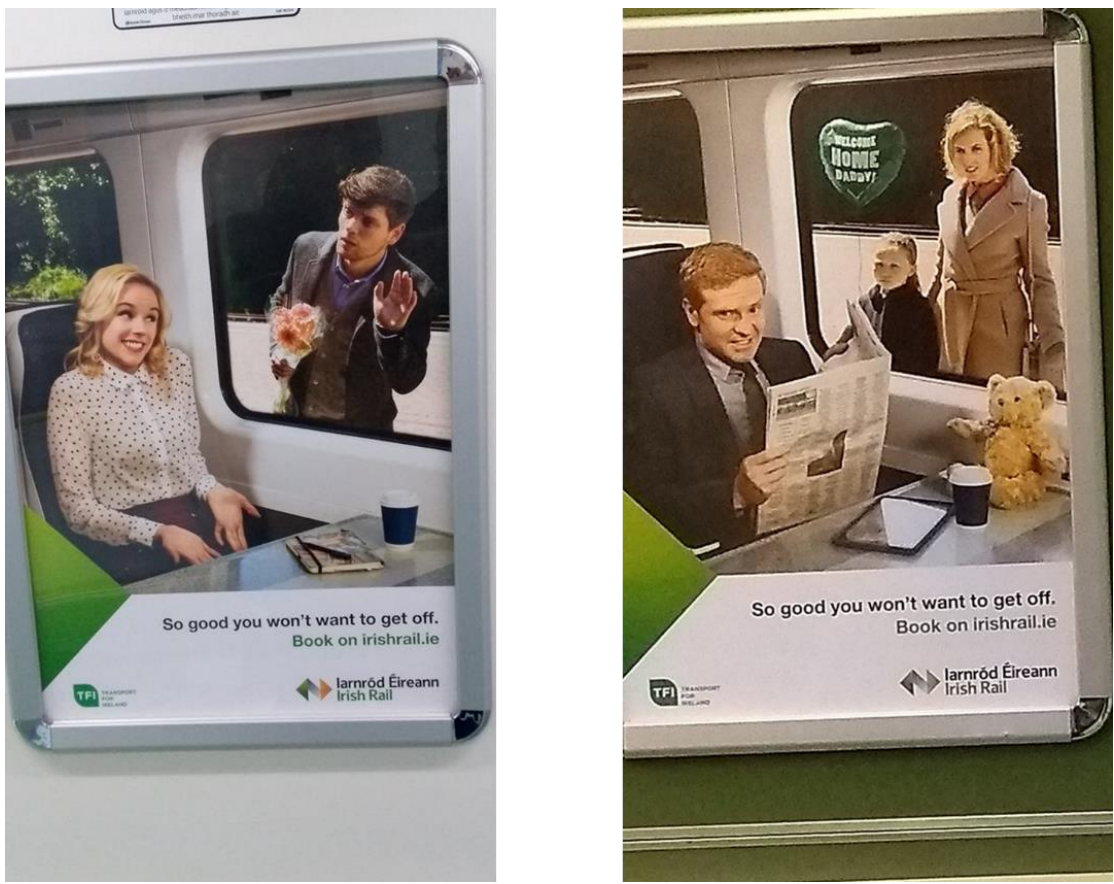

Figure 1. Billboards of Irish Rail 2017 by Publicis Dublin (Director: John Butler, Creative Director: Carol Lambert, Copywriter: Peter

(C) Sabrina Mazzali-Lurati et al. Informal Logic, Vol. 39, No. 4 (2019), pp. 497-530 
Dobbyn, Art Director: Neil Hanratty, Agency Producer: Rachel Murray, Producer: Lorraine Geoghan, Account Director: Jimmy Murphy, Account Manager: Karen Austin, Sound: Will Farrell, Client: Stephen Murray/Charlotte Tucker)
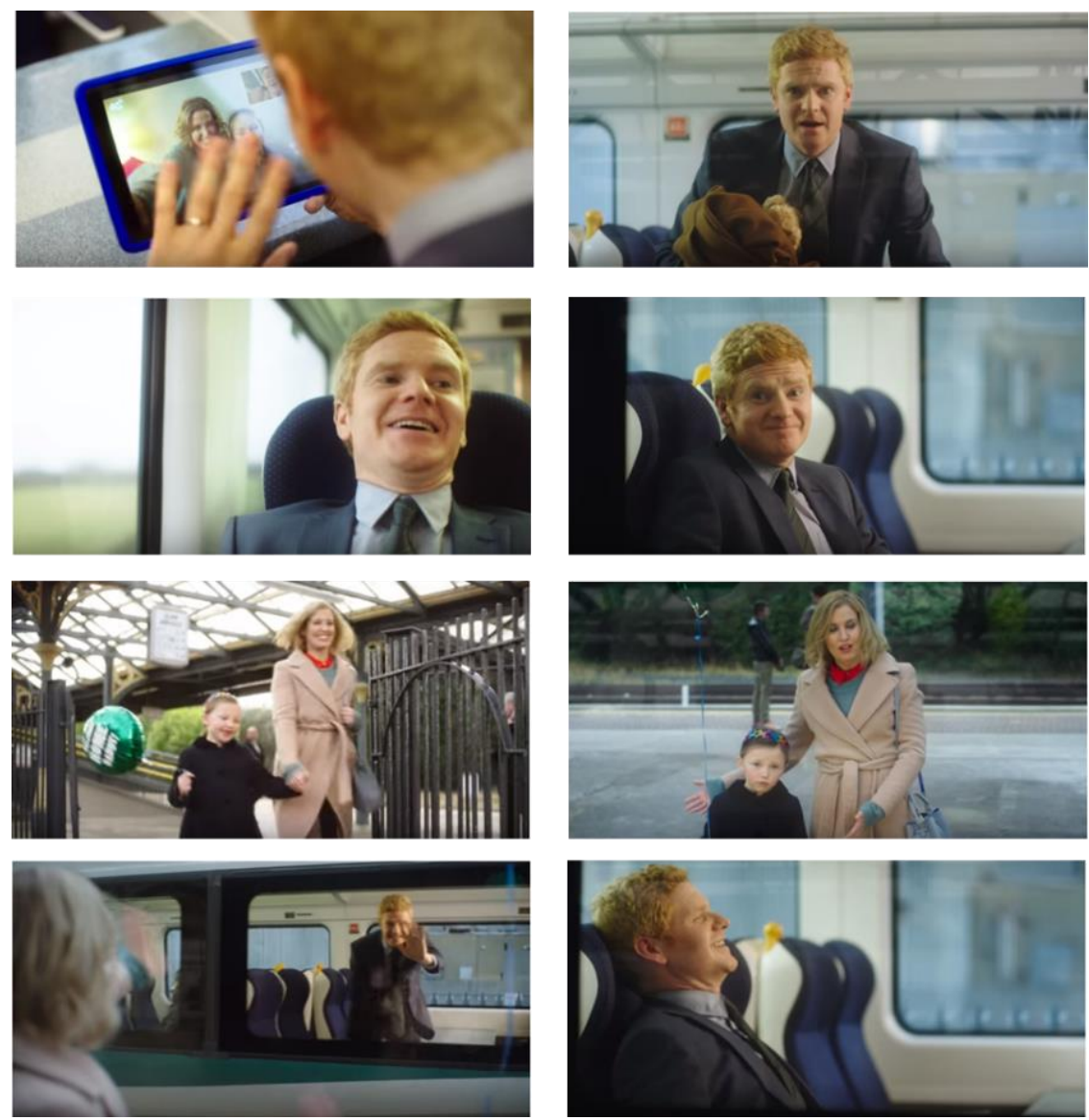

Figure 2. Selected shots from the TV commercial for Irish Rail 2017 (https://www.youtube.com/watch?v=LHvGXh4xsBo) 


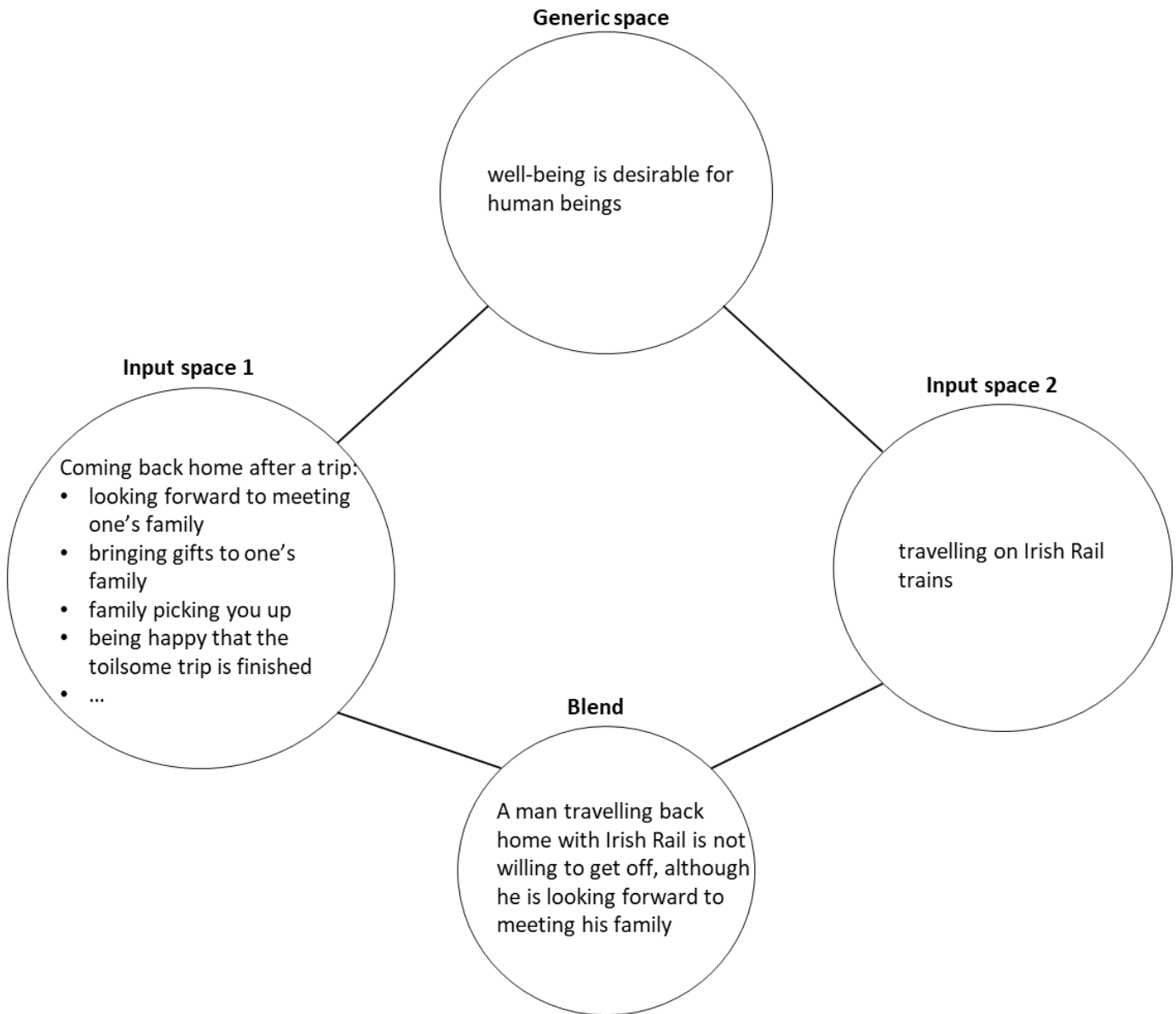

Figure 3. Conceptual integration network for the TV commercial for Irish Rail 2017 
Endoxon: Meeting one's family after a trip is an important value/desire.

Datum: A person travelling back home with Irish Rail does not get off and accepts not to meet her/his family.
Locus from final-instrumental cause

Maxim: If a person chooses $\mathrm{X}$ instead of an important value/desire, then $X$ must be very good.

First conclusion - Minor premise: The person chooses to stay on Irish Rail

train instead of taking action related to an important value/desire.

Endoxon: It is desirable to travel on good trains that make your trip comfortable.

Final conclusion/Datum: Irish Rail trains are very good.
Locus from

final-instrumental

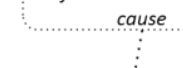

Maxim: If $X$ causes

something desirable, it is

desirable to use it.

Final conclusion: It is desirable to use Irish Rail.

Figure 4. AMT diagram for the TV commercial for Irish Rail 2017 


\section{Appendix 2. Sagrotan 2016}
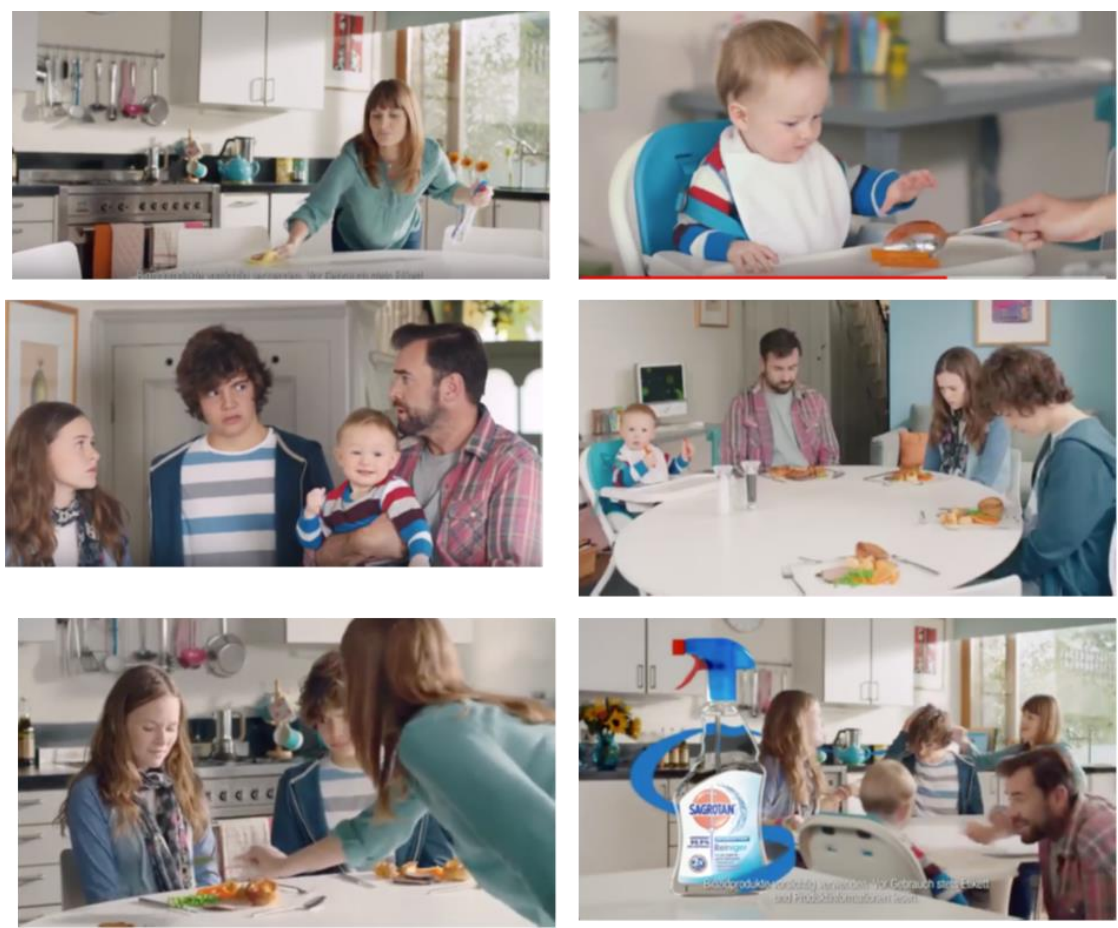

Figure 1. Selected shots from the TV commercial for Sagrotan 2016 (Agency Producer: Citigate Demuth in Frankfurt/Main) (https://www.youtube.com/watch?v=Zh61lpyoCis) 


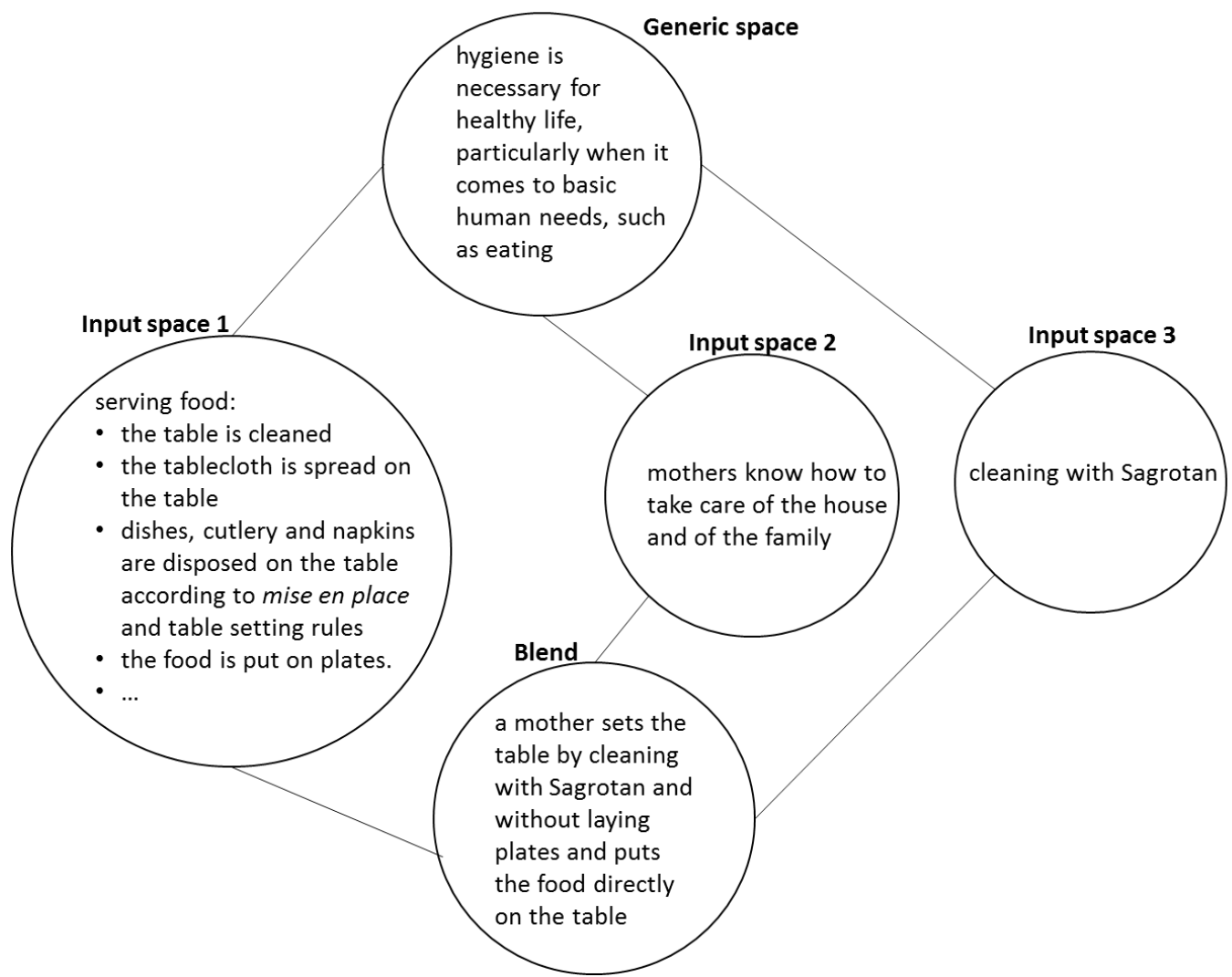

Figure 2. Conceptual integration network for the TV commercial for Sagrotan 2016

(C) Sabrina Mazzali-Lurati et al. Informal Logic, Vol. 39, No. 4 (2019), pp. 497-530 


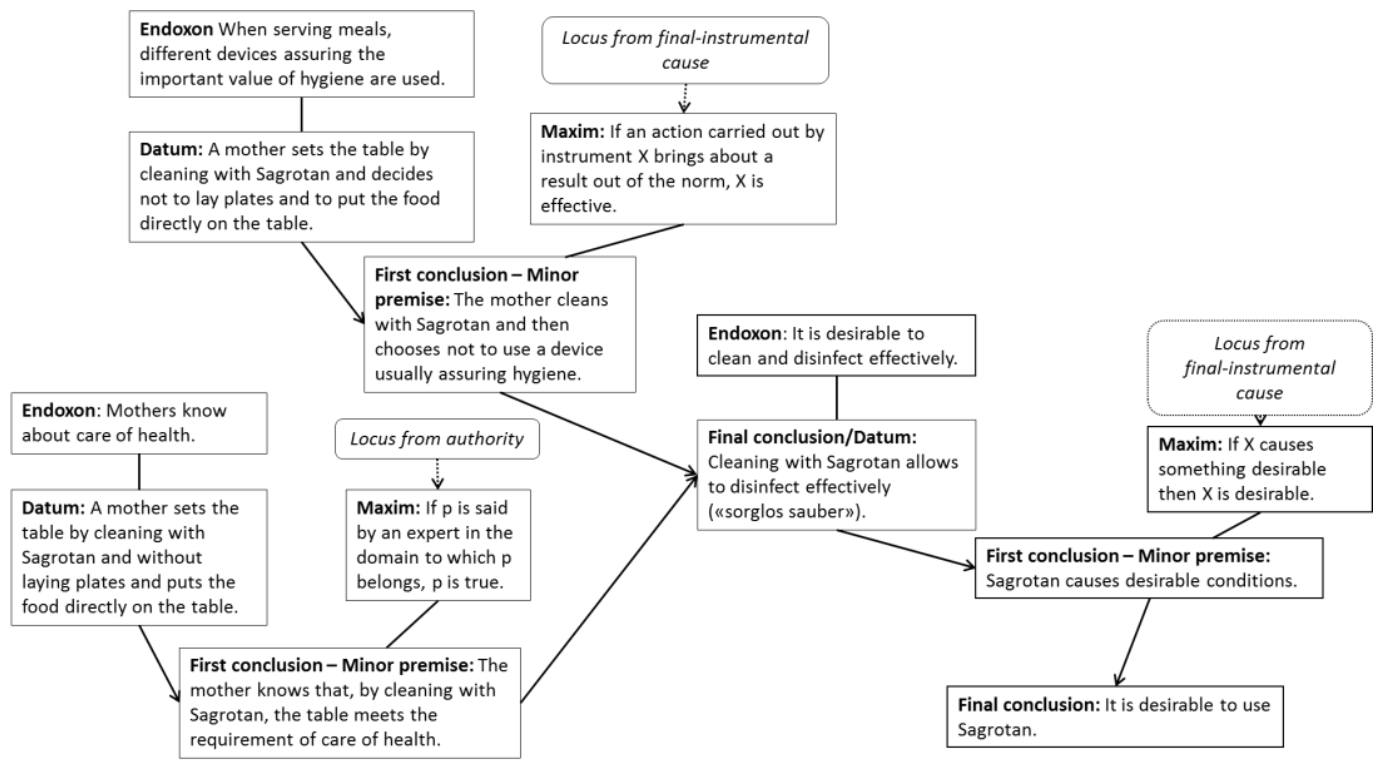

Figure 3. AMT diagram for the TV commercial for Sagrotan 2016

\section{Appendix 3. Sonicare}

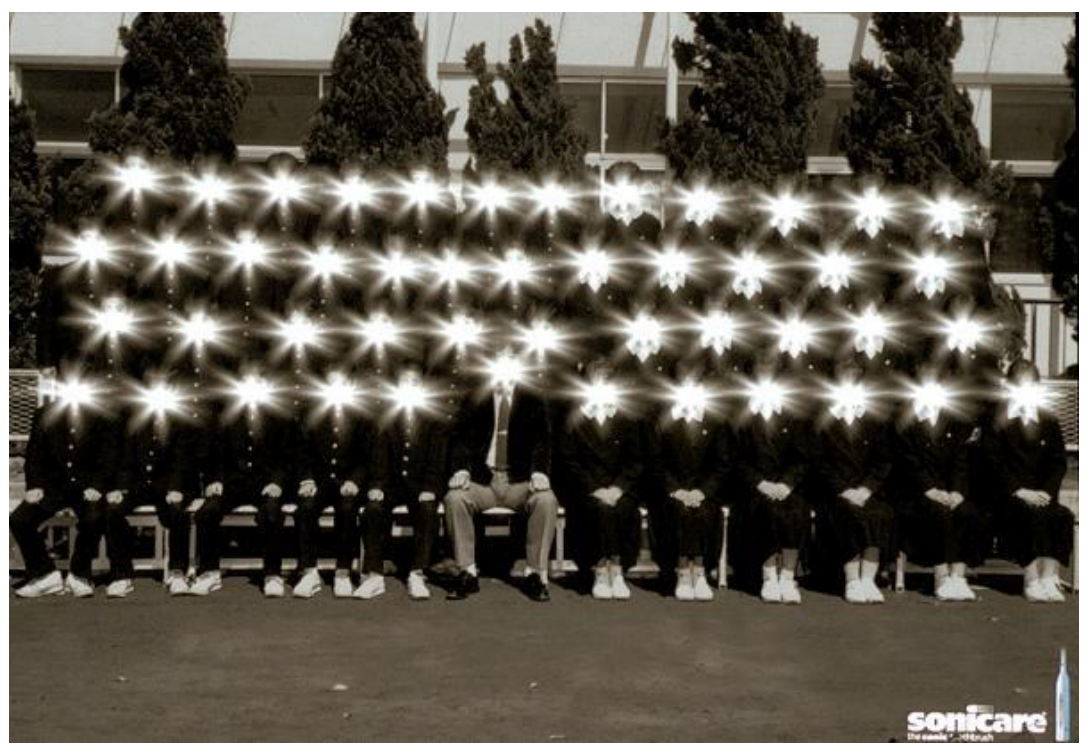

Figure 1. Sonicare Electric Toothbrush's ad (Goldenberg et al. 2009, p. 98)

(C) Sabrina Mazzali-Lurati et al. Informal Logic, Vol. 39, No. 4 (2019), pp. 497-530 


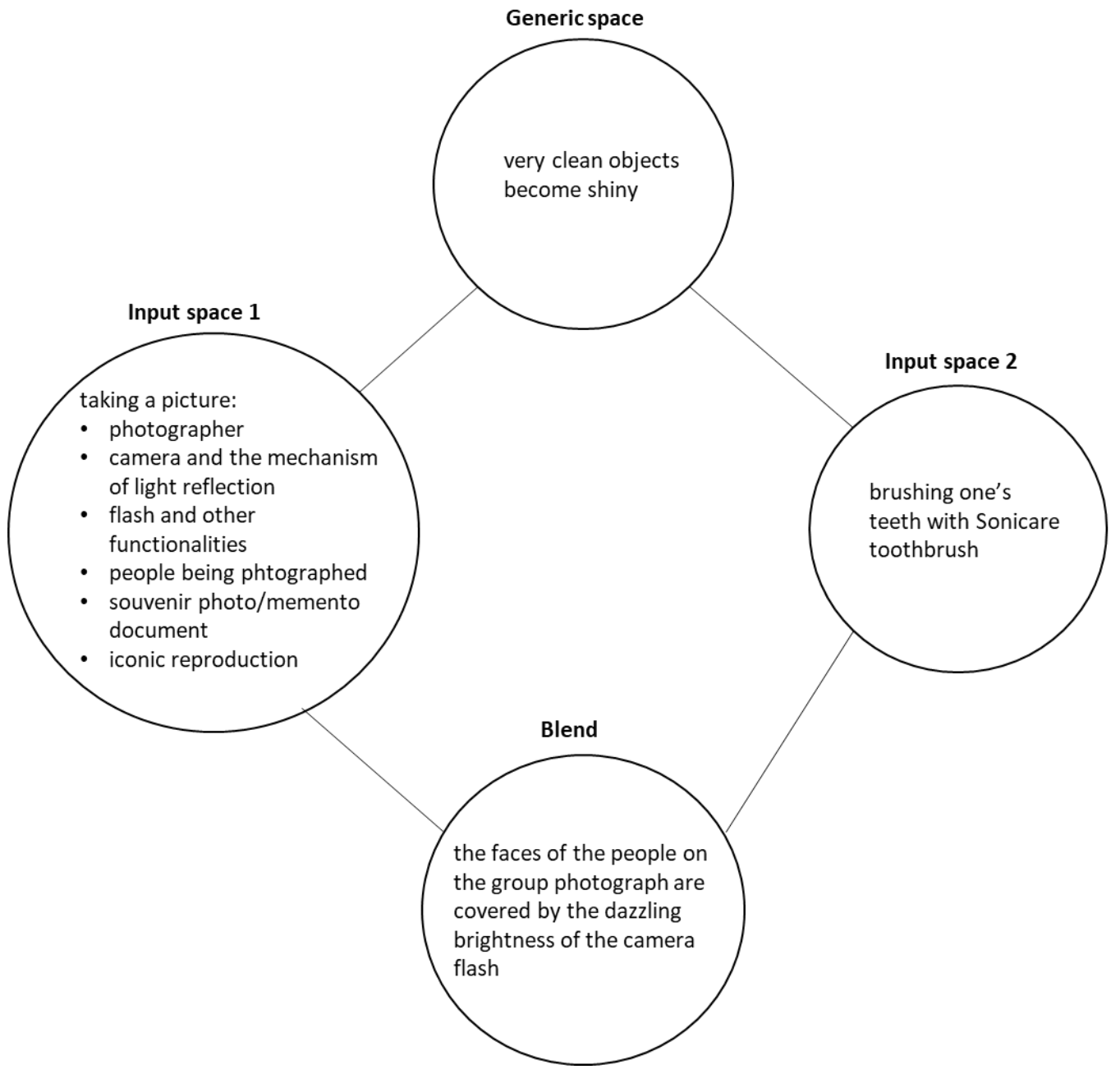

Figure 2. Conceptual integration network for Sonicare's ad

(C) Sabrina Mazzali-Lurati et al. Informal Logic, Vol. 39, No. 4 (2019), pp. 497-530 
Endoxon: Mothers know about care of health.

\section{Datum: A mother sets the} table by cleaning with Sagrotan and without laying plates and puts the food directly on the table.
First conclusion - Minor premise: The mother knows that, by cleaning with Sagrotan, the table meets the requirement of care of health.

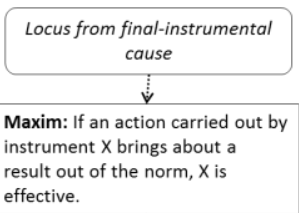

First conclusion - Mino premise: The mother cleans with Sagrotan and then chooses not to use a device usually assuring hygiene.

Endoxon: It is desirable to clean and disinfect effectively.

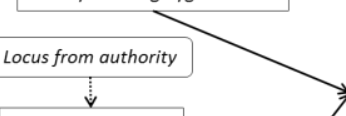

Maxim: If $p$ is said by an expert in the domain to which $\mathrm{p}$ belongs, $\mathrm{p}$ is true.

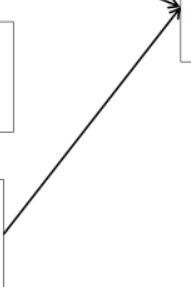
Conclusion/Datum: Cleaning with Sagrotan allows to disinfect effectively ("sorglos sauber»).
Locus from final-instrumental cause

Maxim: If $X$ causes something desirable then $\mathrm{X}$ is desirable.

Figure 3. AMT diagram for Sonicare's ad

(C) Sabrina Mazzali-Lurati et al. Informal Logic, Vol. 39, No. 4 (2019), pp. 497-530 


\section{Appendix 4. Acquasoft}
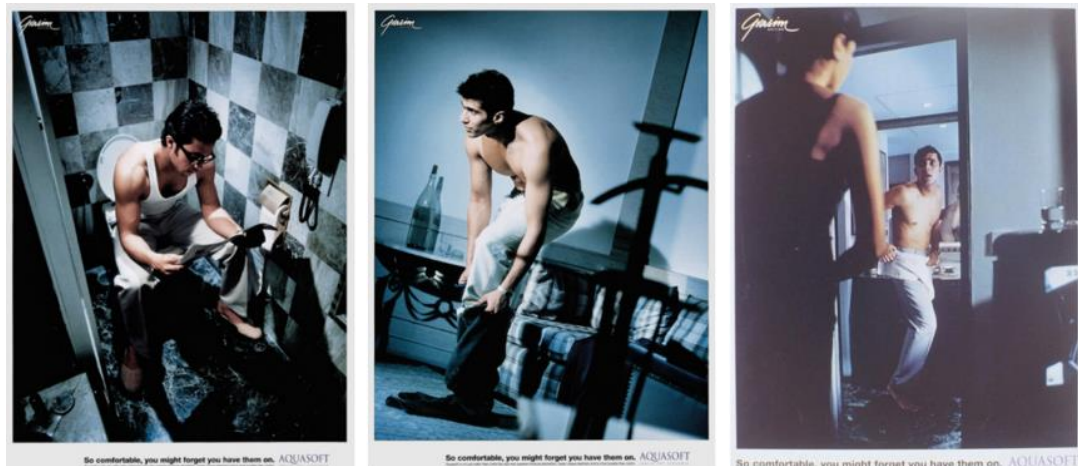

Figure 1. Grasim Acquasoft fabric ads (Goldenberg et al. 2009: 99)

(C) Sabrina Mazzali-Lurati et al. Informal Logic, Vol. 39, No. 4 (2019), pp. 497-530 


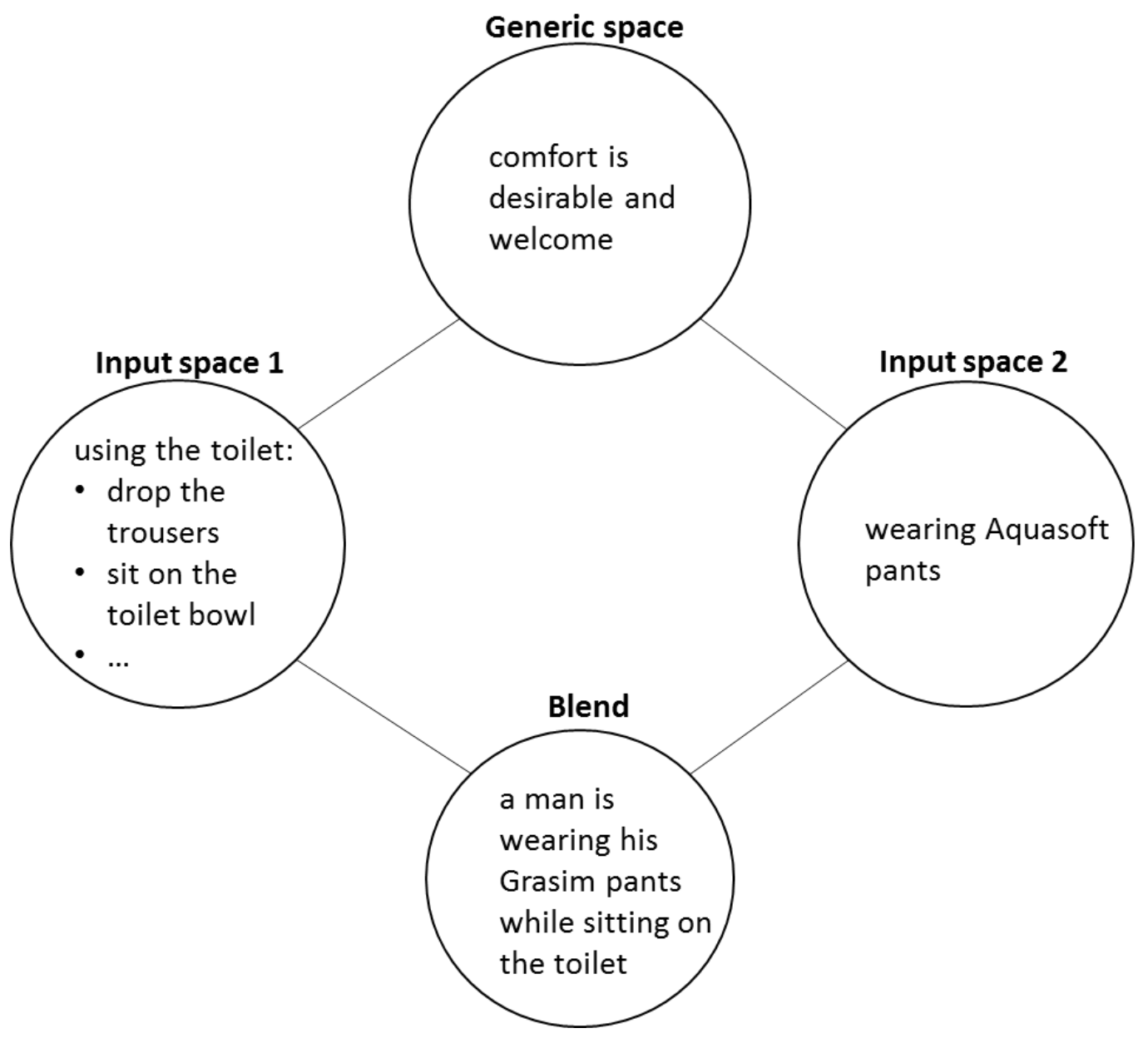

Figure 2. Conceptual integration network for the first ad above for Acquasoft fabric 


\section{Sabrina Mazzali-Lurati, Chiara Pollaroli \& Daniela Marcantonio}

Endoxon: One must be naked in order to comfortably use the toilet.

Datum: A man sitting comfortably on the toilet is wearing his Grasim pants made with Aquasoft.
First conclusion - Minor premise:

The man wearing Aquasoft pants

feels naked.

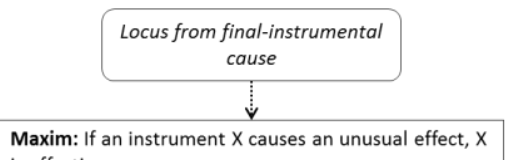

is effective.

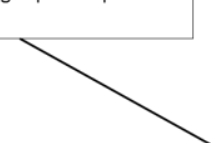

Endoxon: Unperceivable pants are desirable in order to feel comfortable.

Final conclusion/Datum:

Grasim pants made with

Aquasoft are unperceivable.

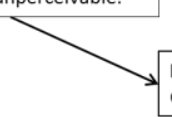

First conclusion - Minor premise:

Grasim causes something desirable.

Final conclusion: It is desirable to use Grasim pants.

Figure 3. AMT diagram for the first ad above for Acquasoft fabric

(C) Sabrina Mazzali-Lurati et al. Informal Logic, Vol. 39, No. 4 (2019), pp. 497-530 